\title{
Comparative Study between Infraclavicular Subomohyoid Block (Iso Block) and Interscalene Block During Shoulder Surgery under General Anaesthesia
}

A.F.Yousof, A.F.Abo Shady, A.H.Abdelrahman and M.M.Abouseeda

Anaesthesia and Intensive Care Dept., Faculty of Medicine, Benha Univ., Benha, Egypt

E-Mail:Marwa85@gmail.com

\begin{abstract}
Interscalene nerve block (IS block) is the pain relief standard for shoulder surgery. But ISB is invasive and associated with complications. Infraclavicular Subomohyoid block (ISO block) may be an alternative; but evidence of comparative efficacy is sparse. We examine whether ISO block is non-inferior to IS block for pain after shoulder surgery. is to compare the efficacy of Infraclavicular Subomohyoid block (ISO block) versus Interscalene block (IS block) analgesia in shoulder arthroscopy enlightening the pros and cons of each block.This study was done at Benha university hospitals. It is a Prospective, single blind randomized clinical study which compared between infraclavicular subomohyoid block (ISO block) versus interscalene block (IS block), in outcome, the study included 90 patients udergoing elective shoulder arthroscopy, divided into three groups. The first group (group I) received general anaesthesia then infraclavicular subomohyoid block; the second group (group II) received general anaesthesia then interscalene block; the third group (group III) general anaesthesia was done. Is high significant difference between groups as regard VAS after 6, 12, 18and 24 hours after injection, also as regard pain rescue analgesia.Compared with the interscalene block, the infraclavicular subomohyoid block resulted in a significantly less frequent phrenic nerve block and overall complications and with slightly difference in postoperative analgesia.
\end{abstract}

Keywords: Interscalene blocks, Shoulder arthroscopy, ISO block, General Anaesthesia, prospective.

\section{Introduction}

Shoulder surgery can be performed under regional or general anaesthesia. Interscalene brachial plexus block has been used for a variety of procedures about the shoulder, including instability repairs, proximal humeral prosthetic replacements, total shoulder arthroplasties, anterior acromioplasties, rotator cuff repairs, and operative treatment of humeral fractures, for both arthroscopic or open approach. These blocks have resulted in good surgical anesthesia, a minimum of complications, and a high degree of patient acceptance [1].

Regional anesthesia has been credited with having several advantages over general anesthesia for shoulder surgery. These include excellent muscle relaxation, less blood loss, shorter hospital stay, reduced postoperative analgesia requirements, and avoidance of the risks and side effects of general anesthesia, especially in patients with underlying medical conditions in whom general anaesthesia may place the patient at significant risk [2].

An interscalene block will consistentely block $\mathrm{C} 4$ and $\mathrm{C} 3$ as well as $\mathrm{C} 5, \mathrm{C} 6$, and $\mathrm{C} 7$. Cervical nerve roots C8 and T1 are blocked approximately 40 to $60 \%$ of patients. The commonly used superior and deltopectoral surgical approaches are within the dermatomes anesthetized by an ISB. The lower anterior aspect of the shoulder and the dorsal aspect as well, are innervated by thoracic nerve roots $\mathrm{T} 2$ and $\mathrm{T} 3$. These areas can be blocked combining an ISB with a subcutaneous infiltration of local anesthetic to cover a larger surgical incision [2].

For infraclavicular block (posterior technique) [3], the linear ultrasoumd probe is placed at the infraclavicular region to identify the cords of brachial plexus (in a short cut). To block the suprascapular nerve (subomohyoid technique) [4] the linear probe is repositioned between the needle and the clavicle and adjusted to identify the inferior belly of omohyoid longitudinally.

\section{Subjects and methods}

\subsection{Methods of randomization}

Patients were randomized into three equal groups. An online randomi zation program was used to generate random number list. Patient randomization numbers were concealed in opaque envelopes which were opened by the study investigator.

\subsection{Methods of blindness}

Members of the study group involved in obtaining functional data were blinded to randomization for the period of data acquisition and analysis.

\subsection{Inclusion Criteria}

Age from 18 to 65 years, ASA physical status: I, II and III and Type of operations: Patients undergoing shoulder surgery.

\subsection{Exclusion Criteria}

Patients with BMI $<18.5$ or $>30 \mathrm{~kg} / \mathrm{m}^{2}$, Patients with coagulation disorders, Local skin infection at the site of injection, Patients with known allergy to one of the used drugs.

\subsection{Groups allocation}

Ninety Patients were randomly allocated into three equal groups:

$>$ Group I ISO block (ISO): received general anaesthesia then infraclavicular subomohyoid block.

$>$ Group II Interscalene block (ISC): received general anaesthesia then interscalene block.

$>$ Group III general anaesthesia (GA): received general anaesthesia. 


\section{Preoperative visit}

One day before surgery all patients were interv i ewed to explain visual anal ogue scale (VAS). Also routine investigntions in the form of twelve leads electrocardiography (ECG), complete blood count $(\mathrm{CBC})$, coagulation profile (bleeding time, prothrombin time, international normalized ratio and partial thromboplastin time), liver functions, and kidney functions were fulfilled.

\subsection{General anaesthesia for all groups}

\subsection{Regional block techniques for Group 1 and Group II}

Technique in both groups was performed and confirmed with ultrasound (GE® LOGIQ P5 digital ultrasound system, china

The needle is inserted $2-3 \mathrm{~cm}$ superior to the clavicle and advanced (using an in plane technique) posterior to the clavicle, towards the cords, and local anaesthetic $25-30 \mathrm{ml}$ is injected.

To block the suprascapular nerve (subomohyoid technique), the linear probe is repositioned bet ween the needl $\mathrm{e}$ and the clavic le and adjusted to identify the inferor belly of omohyoid longitudinally. The needle tip is the redirected (using the out-of-plane technique) towards the interfacial plane deep to the omohyoid between the omohyoid and subscapularis/serratus anterior muscles), where local anaesthetic $5 \mathrm{ml}$ is injected. This injection is more lateral than the previously described to minimize medial spread.

\section{Technique of (ISC) interscalene block}

GOAL: With the patient in the proper position, the skin is disinfected and the transducer is positioned in the transverse plane to identify the carotid artery. Once the artery is identified, the transducer is moved slightly laterally across the neck.

The needle is then inserted in-plane toward the brachial plexus ,typically in a lateral-to-medial direction, although medial-to- lateral needle orientation can be also chosen if more convenient. After a careful aspiration to rule out an intravascular needle placement, 1 to $2 \mathrm{ml}$ of local anaesthetic is injected to document proper needle placement. Injection of several millimetres of local anaesthetic often displaces the brachial plexus away from the needle.

Injection of 25 to $30 \mathrm{ml}$ is adequate when visualisation of the brachial plexus between the scalene muscles proves difficult; the transducer is lowered to the supraclavicular fossa. At this position, the brachial plexus is identified lateral and superficial to the subclavian artery. From here, the brachial plexus is traced cranially to the desired level (the traffic light appearance between the anterior and middle scalene muscles).

\section{Results}

Table (1) this table shows that mean \pm SD of age is $43.07 \pm 14.32,15.21 \pm 42.77$ and $42.77 \pm 14.08$ years old in the three groups respectively and there was no statistical significant difference between the studied three groups as regard age, BMI and duration of surgery.

Table (2) This table shows that there was statistical significant difference between three groups as regard baseline VAS and there is highly statistical significant difference between groups as regard VAS after 6, 12, 18and 24 hours after injection, also as regard pain rescue analgesia there is highly statistical significant difference between groups.

Table (3) This table shows that there is no statistical difference between groups as regard HR preoperatively, while there is highly statistical significant difference between the three groups as regard heart rate at skin incision, postoperative, after 6 hours, after $12 \mathrm{~h}$, after $18 \mathrm{~h}$ and after 24 hours.

Table (4) This table shows that there is no statistical difference between groups as regard MAP ${ }^{\cdots}$ preoperatively, while there is highly statistical significant difference between the three groups as regard MAP at postoperative, after 6 hours, after $12 \mathrm{~h}$, after $18 \mathrm{~h}$ and after 24 hours.

Table (5) This table shows distribution of the studied groups as regard complications, revealing that there is statistical significant difference between the three groups regarding Diaphragmatic hemiparesis (ipsilateral phrenic nerve block), while there is no statistical significant difference between them regarding other complications as Pneumothorax Blockade of vagus, recurrent laryngeal and cervical sympathetic nerves (Horner's syndrome), Epidural or subarachnoid injection, Vertebral artery injection and Severe hypotension and bradycardia (Bezold-Jarisch reflex).

Table (1) Distribution of the studied cases according to socio-demographic data $(n=90)$.

\begin{tabular}{lcccccccc}
\hline & Mean & $\mathbf{\pm S D}$ & Mean & $\mathbf{\pm S D}$ & Mean & $\mathbf{\pm S D}$ & $\mathbf{F}$ test & \\
\hline Age & 43.07 & 14.32 & 41.17 & 15.21 & 42.77 & 14.08 & 0.15 & 0.86 \\
BMI (kg/m2) & 23.7 & 3.23 & 23.08 & 3.32 & 22.93 & 2.74 & 0.51 & 0.60 \\
$\begin{array}{l}\text { Duration of } \\
\text { Surgery }\end{array}$ & 107.67 & 32.77 & 102.0 & 29.17 & 99.67 & 29.88 & 0.54 & 0.58 \\
\hline
\end{tabular}


Table (2) Distribution of the studied three groups as regard Visual analogue pain scale.

\begin{tabular}{lcccccccc}
\hline & Mean & $\mathbf{\pm S D}$ & Mean & $\mathbf{\pm S D}$ & Mean & $\mathbf{\pm S D}$ & F test & \\
\cline { 2 - 7 } VAS0 & 1.9 & 0.92 & 1.8 & 0.96 & 2.5 & 1.17 & 4.11 & $0.02^{*}$ \\
VAS6 & 1.37 & 0.72 & 1.43 & 0.82 & 2.27 & 1.08 & 9.62 & $<0.001^{* *}$ \\
VAS12 & 1.23 & 0.73 & 1.3 & 0.65 & 2.4 & 1.0 & 19.7 & $<0.001^{* *}$ \\
VAS18 & 1.4 & 0.56 & 1.43 & 0.73 & 2.37 & 1.07 & 13.66 & $<0.001^{* *}$ \\
VAS24 & 1.33 & 0.48 & 1.37 & 0.56 & 2.17 & 0.75 & 18.27 & $<0.001^{* *}$ \\
Pain rescue & 0.33 & 1.27 & 0.65 & 1.72 & 3.67 & 5.4 & 8.22 & $0.001^{* *}$ \\
analgesia & & & & & & & & \\
\hline
\end{tabular}

Table (3) Distribution of cases in the three groups according to heart rate.

\begin{tabular}{|c|c|c|c|c|c|c|c|c|}
\hline & Mean & \pm SD & Mean & \pm SD & Mean & \pm SD & F test & \\
\hline HR0 (pre-op) & 74.83 & 8.36 & 74.83 & 8.56 & 78.17 & 9.05 & 1.48 & 0.23 \\
\hline HR1 (skin incision) & 70.33 & 6.81 & 71.0 & 7.12 & 79.5 & 8.84 & 13.41 & $<0.001 * *$ \\
\hline HR2 (post-op) & 67.67 & 7.63 & 69.17 & 6.31 & 80.17 & 6.88 & 28.85 & $<0.001 * *$ \\
\hline HR3 (after 6h) & 68.17 & 6.36 & 68.17 & 5.17 & 81.5 & 6.97 & 46.09 & $<0.001 * *$ \\
\hline HR4 (after 12h) & 70.0 & 5.25 & 70.67 & 5.04 & 82.33 & 6.79 & 43.7 & $<0.001 * *$ \\
\hline HR5 (after18h) & 70.0 & 5.25 & 70.67 & 5.04 & 82.0 & 6.24 & 44.52 & $<0.001 * *$ \\
\hline HR6 (after 24) & 69.33 & 4.3 & 70.33 & 4.72 & 82.17 & 5.83 & 61.36 & $<0.001 * *$ \\
\hline
\end{tabular}

Table (4) Distribution of the studied groups as regard mean arterial blood pressure.

\begin{tabular}{lcccccccc}
\hline & Mean & $\mathbf{\pm S D}$ & Mean & $\mathbf{\pm S D}$ & Mean & $\mathbf{\pm S D}$ & $\mathbf{F}$ test & \\
\cline { 2 - 6 } MAP0 (pre-op) & 78.17 & 7.71 & 79.0 & 6.87 & 77.0 & 7.61 & 0.55 & 0.58 \\
MAP1 (skin incision) & 75.67 & 6.66 & 76.67 & 6.07 & 77.83 & 6.11 & 0.89 & 0.41 \\
MAP2 (post-op) & 74.83 & 5.94 & 74.67 & 4.9 & 80.83 & 6.83 & 10.48 & $<0.001^{* *}$ \\
MAP3 (after 6h) & 76.83 & 6.09 & 76.33 & 6.94 & 85.17 & 6.88 & 16.71 & $<0.001^{* *}$ \\
MAP4 (after 12h) & 74.83 & 5.8 & 75.5 & 6.48 & 85.0 & 6.16 & 25.65 & $<0.001^{* *}$ \\
MAP5 (after18h) & 74.5 & 5.92 & 75.5 & 6.48 & 85.17 & 5.8 & 28.22 & $<0.001^{* *}$ \\
MAP6 (after 24) & 74.5 & 5.92 & 75.17 & 6.5 & 85.17 & 5.8 & 28.98 & $<0.001^{* *}$ \\
\hline
\end{tabular}

Table (5) Distribution of the studied groups as regard complications .

\begin{tabular}{|c|c|c|c|c|c|c|c|c|}
\hline Complications & NO & $\%$ & NO & $\%$ & NO & $\%$ & & \\
\hline $\begin{array}{l}\text { Diaphragmatic hemiparesis } \\
\text { (ipsilateral phrenic nerve block) }\end{array}$ & 3 & 10.0 & 9 & 30.0 & 0 & 0.0 & $\begin{array}{l}\mathrm{FET}= \\
11.85\end{array}$ & $0.002 * *$ \\
\hline Pneumothorax & 1 & 3.3 & 4 & 13.3 & 0 & 0.0 & $\mathrm{FET}=4.47$ & 0.122 \\
\hline $\begin{array}{l}\text { Blockade of vagus,recurrent } \\
\text { larryngeal and cervical } \\
\text { sympathetic nerves (Horner,s } \\
\text { syndrome) }\end{array}$ & 1 & 3.3 & 3 & 10.0 & 0 & 0.0 & $\mathrm{FET}=3.03$ & 0.32 \\
\hline $\begin{array}{l}\text { Epidural or subarachnoid } \\
\text { injection }\end{array}$ & 1 & 3.3 & 1 & 3.3 & 0 & 0.0 & $\mathrm{FET}=1.27$ & 1.0 \\
\hline Vertebral artery injection & 0 & 0.0 & 0 & 0.0 & 0 & 0.0 & - & - \\
\hline $\begin{array}{l}\text { Severe hypotension } \quad \text { and } \\
\text { bradycardia } \\
\text { reflex) }\end{array}$ & 1 & 3.3 & 1 & 3.3 & 0 & 0.0 & $\mathrm{FET}=1.27$ & 1.0 \\
\hline
\end{tabular}

\section{Discussion}

Shoulder surgery is the second most common orthopedic procedure. It usually results in intense postoperative pain, the control of which may require the use of large doses of opioids. Interscalene block is the standard block for shoulder surgery. It blocks the brachial plexus (BP) thereby providing adequate postoperative analgesia and improving the rehabilitation. However, it results in phrenic nerve block (PrNB) and hemi-diaphragmatic paresis which impairs the respiratory mechanics markedly [5].
This is a Prospective single blind randomized clinical study that was conducted on 90 patients were randomized into three equal groups:

In the present study we assessed the sociodemographic characteristics of the studied groups and revealed that that mean $\pm \mathrm{SD}$ of age is $43.07 \pm 14.32,15.21 \pm 42.77$ and $42.77 \pm 14.08$ years old in the three groups respectively and there was no statistical significant difference between the studied three groups as regard age, BMI and duration of surgery. 
In agreement with our results, the study of Taha et al., [6] that aimed to compare the phrenic nerve block incidence (primary outcome) and the analgesic efficacy (secondary outcomes) between the LVSB and ISO block and found that mean age of patients in two groups was 49.1 (13.8) and $44.2 \quad$ (13.6) respectively, and there was no statistical significant difference between them as regard neither age, sex, BMI and duration of operation.

The study on the hand expressed that there was statistical significant difference between three groups as regard baseline VAS and there is highly statistical significant difference between groups as regard VAS after 6, 12, 18 and 24 hours after injection, also as regard pain rescue analgesia there is highly statistical significant difference between groups.

In previous study of Kumara et al., [7] VAS was recorded at specified intervals between the two groups post-operatively. Group SSB showed higher mean VAS scores compared to Group ISB during first $6 \mathrm{~h}$, which was statistically significant till first $2 \mathrm{~h}$. Verbal pain scores between groups showed statistical significant values up to $4 \mathrm{~h}$ interval, at $6 \mathrm{~h}$ interval scores were comparable between the groups and at $24 \mathrm{~h}$ interval scores were almost similar.

Another study of Lee et al., [8] revealed that no significant difference in the VAS score was found between the two groups when the scores were assessed in the patient room before the surgery. The VAS score by time was significantly higher in Group 2 than in Group 1. No significant difference was found 24 hours after the surgery $(\mathrm{P}<0.05$

Additionally, the current study illustrated that there is no statistical difference between groups as regard HR preoperatively, while there is highly statistical significant difference between the three groups as regard heart rate at skin incision, postoperative, after 6 hours, after $12 \mathrm{~h}$, after $18 \mathrm{~h}$ and after 24 hours.

A study of Lee et al., [8] reported that The systolic and diastolic blood pressures and heart rates changed more significantly in Group 1, which underwent IBPB using normal saline after skin incision, than in Group 2 , which underwent IBPB using $0.5 \%$ ropivacaine $(\mathrm{P}<$ 0.05 , In Group 1, significantly elevated systolic and diastolic blood pressures were measured at all-time points, unlike before the skin incision. The heart rate significantly increased at all the time points, except at 20 min after the skin incision ( $\mathrm{P}<0.05)$. In Group 2, elevated systolic and diastolic blood pressures occurred only $5 \mathrm{~min}$ after the skin incision. No significant change in heart rate was seen, except $3 \mathrm{~min}$ after the skin incision $(\mathrm{P}<0.05)$. No hypertension, hypotension, and bradycardia that required drug treatment was found in both groups.

Also in the study on the hand, we assessed the MAP and revealed that that there is no statistical difference between groups as regard MAP preoperatively, while there is highly statistical significant difference between the three groups as regard MAP at skin incision, postoperative, after 6 hours, after $12 \mathrm{~h}$, after $18 \mathrm{~h}$ and after 24 hours.

As no reports of hemodynamic instability such as increased blood pressure and heart rate during arthroscopic shoulder surgery have been suggested in previous studies, a few causes were hypothesized before this study. First, hemodynamic instability could be caused by surgical manipulation during anesthesia. Morrison et al., [9] reported that the difference between systolic blood pressure and shoulder joint pressure should be maintained at $49 \mathrm{mmHg}$ or lower to secure the surgery field in their study on the relationship between shoulder joint pressure, blood pressure, and surgery field in arthroscopic shoulder surgery.

Infraclavicular Subomohyoid block (ISO block) and Interscalene block (IS block) analgesia which showed stable hemodynamic changes during arthroscopic shoulder surgery, is an effective method to control early pain 24 hours after surgery.

Singelyn et al., [10] reported that IBPB showed a greater analgesic effect than the suprascapuler nerve block or intra-articular injection for 24 hours after the surgery. Furthermore, they showed that IBPB reduced the requirement for narcotic analgesics after the surgery and minimized the risk of post-operative nausea and vomiting. IBPB complications have been reported from time to time. Whitaker et al., [11] reported that severe hypotension occurred during arthroscopic shoulder surgery after IBPB.

Finally, the present study assessed the complications among the three groups revealed that there is statistical significant difference between the three groups regarding Diaphragmatic hemiparesis (ipsilateral phrenic nerve block), while there is no statistical significant difference between them regarding other complications as Pneumothorax Blockade of vagus, recurrent laryngeal and cervical sympathetic nerves (Horner's syndrome), Epidural or subarachnoid injection, Vertebral artery injection and Severe hypotension and bradycardia (Bezold-Jarisch reflex).

Many studies have demonstrated that ISB is the most efficient regional analgesic technique in shoulder arthroscopic surgery. ISB, alone or supplemented with superficial cervical plexus block to ensure the blockade of the supraclavicular nerve results in success rates of $87-100 \%$ [12], However it is associated with potentially serious complications include inadvertent epidural and spinal anaesthesia, vertebral artery injection, paralysis of vagus, recurrent laryngeal, and cervical sympathetic nerve, pneumothorax and injury to the brachial plexus. Phrenic nerve block occurs in all patients undergoing interscalene nerve block [13].

In conclusion, compared with the interscalene block, the infraclavicular subomohyoid block resulted in a significantly less frequent phrenic nerve block and overall complications and with slightly difference in postoperative analgesia. Therefore, it may be relevant to consider for patients who cannot tolerate a phrenic 
nerve block.

Also we conclude that our prospective randomized study demonstrated efficacy of interscalene block with GA for intra-operative analgesia in arthroscopic shoulder surgeries. However ISB with GA is also a safe and simple alternative technique for this purpose.

\section{Conclusion}

Compared with the interscalene block, the infraclavicular subomohyoid block resulted in a significantly less frequent phrenic nerve block and overall complications and with slightly difference in postoperative analgesia. Therefore, it may be relevant to consider for patients who cannot tolerate a phrenic nerve block.

\section{References}

[1] Interscalene brachial plexus block Winnie AP, AnesthAnalg. May-Jun, Vol.49(3), pp.45566,1970 .

[2] Regional anaesthesia for shoulder surgery. R. Anthony Brown MBChB, FFA(SA), Techniques in Regional Anaesthesia and Pain Management, Vol 3 (2), pp. 64-78,1999.

[3] P. Hebbard, G. Royse, ultrasound guided posterior approach to the infraclavicular brachial plexus. Anaesthesia, Vol. 62 ,pp .539,2016.

[4] K .V. Sondekoppam, L.M. Lopera- Veiasquez, L. Naik, S.Ga napatily, Subscapularis and subomohyoi d plane blocks: an alternative to per ipheral nerve blocks for shoulder analgesia. $\mathrm{Br} \mathbf{J}$ Anaesth, Vol.117, PP.831-2,2017.

[5] D.Q. Tran, M.F. Elgueta, J. Aliste, R.J. Finlayson, Diaphragm-sparing nerve blocks for shoulder surgery. Reg Anaesth Pain Med, Vol.42 ,PP. 32- 38,2017.

[6] A.M. Taha, A. Nagib, I. Yurdi Mohamed Elahl, M.Ahmed Abd-Elmaksoud, Diaphragm-sparing effect of the infraclavicular subomohyoid block vs low volume interscalene block. A randomized blinded study, Vol. 30 , PP. 10.1111-13322,2019.

[7] A. Kumara, J.K. Anoop Raj Gogia, Bajaj, Nidhi Agarwal, Clinical evaluation of post-operative analgesia comparing suprascapular nerve block and interscalene brachial plexus block in patients undergoing shoulder arthroscopic surgery, J Clin Orthop Trauma. Jan-Mar, Vol.7(1), PP. 34 39,2016.

[8] H. Y.Lee, S. H.Kim, K. Y.So, D. J .Kim, Effects of interscalene brachial plexus block to intraoperative hemodynamics and postoperative pain for arthroscopic shoulder surgery. Korean journal of anesthesiology, Vol. 62(1), PP. 30-34,2012.

[9] D.S. Morrison, R.K. Schaefer, R.L. Friedman, The relationship between subacromial space pressure, blood pressure, and visual clarity during arthroscopic subacromial decompression . Arthroscopy, Vol.11, PP.557-560,1995.

[10] F.J.Singelyn, L.Lhotel, B.Fabre , Pain relief after arthroscopic shoulder surgery: a comparison of intraarticular analgesia, suprascapular nerve block, and interscalene brachial plexus block. Anesth Analg, Vol.99, PP.589-592,2004.

[11] E.E. Whitaker, A.L. Edelman, J.H. Wilckens, J.M. Richman, Severe hypotension after interscalene block for outpatient shoulder surgery: a case report. J Clin Anesth, Vol.22, PP.132-134,2010.

[12] E.D.Ritchie, D.Tong, F.Chung , Suprascapular nerve block for postoperative pain relief in arthroscopic shoulder surgery: a new modality? Anesth Analg, Vol.84(6), PP.1306$1312,1997$.

[13] P.A.Laurila, A.Lopponen, T. Kanga-Saarela ,Interscalene brachial plexus block is superior to subacromial bursa block after arthroscopic shoulder surgery. Acta Anaesthesiol Scand, Vol.46, PP.1031-1036,2002. 